\title{
Naltrexone-Buprenorphine Interactions: Effects on Cocaine Self-Administration
}

\author{
Nancy K. Mello, Ph.D., Scott E. Lukas, Ph.D., Jack H. Mendelson, M.D.,
} and John Drieze, M.S.

An opioid mixed agonist-antagonist analgesic, buprenorphine, significantly reduces cocaine self-administration by rhesus monkeys, but the relative contribution of buprenorphine's agonist and antagonist properties to this effect is unclear. This study examined the effects of concurrent treatment with naltrexone, a long-acting mu opioid antagonist, on buprenorphine's effects on cocaine and food self-administration by five rhesus monkeys. Cocaine $(0.5 \mathrm{mg} / \mathrm{kg}$ per injection) and food self-administration ( $1 \mathrm{gm}$ banana pellet) were maintained on a second order fixed ratio 4 (FR4) variable ratio (VR) 16:S schedule of reinforcement. Buprenorphine treatment alone $(0.40 \mathrm{mg} / \mathrm{kg} /$ day $)$ and in combination with ascending doses of naltrexone $(0.05,0.10,0.20$, and $0.40 \mathrm{mg} / \mathrm{kg} /$ day) was compared with naltrexone alone $(0.40 \mathrm{mg} / \mathrm{kg} /$ day $)$ and saline control treatment.

Naltrexone was administered simultaneously or 20 minutes before buprenorphine administration. Each treatment condition was in effect for 10 days.

Buprenorphine alone significantly reduced cocaine self-administration by an average of $53 \%$ in comparison to the saline treatment baseline $(\mathrm{p}<.01)$. When saline was substituted for buprenorphine, each monkey rapidly returned to its prebuprenorphine level of cocaine selfadministration. Food self-administration in all conditions was equivalent to or significantly higher $(\mathrm{p}<.05)$ than food-maintained responding during the saline baseline. When buprenorphine and naltrexone were administered simultaneously, naltrexone significantly attenuated buprenorphine's suppressive effects on cocaine selfadministration ( $\mathrm{p}<.05$ to .01). When naltrexone was administered 20 minutes before buprenorphine, there was a significant naltrexone dose-dependent $(\mathrm{p}<.01)$ decrease in buprenorphine's reduction of cocaine selfadministration in comparison to the initial saline baseline. These data suggest that naltrexone antagonizes the partial mu agonist component of buprenorphine, which may be important for buprenorphine's effects on cocaine self-administration. Moreover, the addition of an opioid antagonist to reduce illicit diversion of buprenorphine might also compromise its effectiveness for treatment of dual dependence on cocaine and opiates. [Neuropsychopharmacology 9:211-224, 1993]
KEY WORDS: Buprenorphine; Cocaine; Naltrexone; Buprenorphine-naltrexone interactions; Cocaine selfadministration
From the Alcohol and Drug Abuse Research Center, McLean Hospital-Harvard Medical School, Belmont, Massachusetts.

Address correspondence to: Nancy K. Mello, Ph.D., Alcohol and Drug Abuse Research Center, McLean Hospital, 115 Mill Street, Belmont, Massachusetts 02178

Received March 3, 1993; revised June 15, 1993; accepted June 29, 1993.
Buprenorphine, an opioid mixed agonist-antagonist analgesic, reduced cocaine self-administration by rhesus monkeys by $72 \%$ to $93 \%$ (Mello et al. 1989, 1990). This effect appeared to be selective for cocaine since food self-administration was initially reduced, but tolerance rapidly developed to buprenorphine's suppressive effects on food-maintained responding. In subsequent studies, we found that daily buprenorphine administration selectively reduced cocaine self-administration for as long as 120 days (Mello et al. 1992a). More recently, we found that daily buprenorphine treatment decreased the reinforcing potency of cocaine in rhesus 
monkey and shifted the cocaine dose-response curve approximately one half to $1 \log$ unit to the right (Drieze et al. 1993; Lukas et al. 1993). Acute administration of buprenorphine to rhesus monkey also reduced rates of cocaine-maintained responding and suppressed the peak response without altering its apparent potency (Winger et al. 1992). Cocaine-base smoking by rhesus monkeys and cocaine self-administration by rats were also reduced by buprenorphine treatment (Carroll et al. 1992; Carroll and Lac 1992). These preclinical data are concordant with clinical evaluations of buprenorphine's effects on cocaine abuse by polydrug abusers. Buprenorphine was significantly more effective than methadone in reducing cocaine self-administration by opiate abusers (Kosten et al. 1989a, 1989b; Rosen and Kosten 1991). Ongoing clinical trials indicate that buprenorphine also significantly decreases cocaine abuse by men who are dually dependent on cocaine and heroin, according to DSM-III-R criteria (Gastfriend et al. 1992, 1993a, 1993b; Mello and Mendelson 1993a, 1993b; Mello et al. 1993b).

Buprenorphine is usually classified as a low-efficacy $\mathrm{mu}$ agonist and has a complex profile of opioid partial agonist and antagonist activity (Jaffe and Martin 1990; Winger et al. 1992). The relative contribution of buprenorphine's agonist and antagonist properties to its effects on cocaine self-administration is unknown. The goal of this study was to determine if concurrent administration of a mu opioid antagonist, naltrexone, would change buprenorphine's effects on cocaine selfadministration. Naltrexone was selected for study because it has a long duration of action comparable to that of buprenorphine (Lee et al. 1988; Lewis et al. 1983). In clinical studies, naltrexone antagonized the effects of opiate agonists for 24 to 48 hours (Martin et al. 1973; Mello et al. 1981; Verebey et al. 1976). In rhesus monkeys, naltrexone's apparent antagonist affinity for $\mathrm{mu}$ opioid receptors has been shown in operant behavioral studies (France et al. 1990; France and Woods 1989). If naltrexone reduced buprenorphine's effects on cocaine self-administration, this would suggest that buprenorphine's partial mu opioid agonist component is of critical importance in its interactions with cocaine. Alternatively, the antagonist component of buprenorphine may be important for its reduction of cocaine selfadministration. Naltrexone, as well as buprenorphine, reduced cocaine self-administration by rhesus monkeys in our earlier studies (Mello et al. 1990). Naltrexone also was more effective than an opioid agonist, methadone, in reducing cocaine abuse by opiate-dependent patients (Kosten et al. 1989a; Rosen and Kosten 1991). If the addition of naltrexone enhanced buprenorphine's effects on cocaine self-administration, this would suggest that buprenorphine's interactions with cocaine are mediated by opioid antagonist activity.

We are unaware of any previous studies of the effects of naltrexone and buprenorphine combinations on cocaine self-administration. There has been some interest in adding naloxone to buprenorphine formulations to reduce the possibility of illicit diversion of buprenorphine (Preston et al. 1988; Weinhold et al 1992). Combinations of buprenorphine $(0.4$ or $0.8 \mathrm{mg} / 70$ $\mathrm{kg}$ ) and naloxone $(0.4$ or $0.8 \mathrm{mg} / 70 \mathrm{~kg})$ reduced the subjective and physiologic effects of buprenorphine in men who were not opiate dependent (Strain et al. 1992). Buprenorphine $(0.4 \mathrm{mg} / 70 \mathrm{~kg})$ in combination with 0.8 mg per $70 \mathrm{~kg}$ of naloxone was never identified as an opiate (Strain et al. 1992). Yet, a lower dose of naloxone $(0.2 \mathrm{mg})$ did not compromise the analgesic effectiveness of $0.3 \mathrm{mg}$ buprenorphine in patients with postoperative pain (Rolly et al. 1986). When naloxone $(0.2 \mathrm{mg}, \mathrm{SC})$ was given in combination with buprenorphine $(0.2$ and $0.3 \mathrm{mg}, \mathrm{SC})$ to methadone-maintained men $(30 \mathrm{mg} /$ day), the opioid abstinence signs induced were less severe than, but qualitatively similar to, those produced by naloxone alone (Preston et al. 1988). Despite its antagonist properties, buprenorphine pro. duced minimal signs of opioid abstinence in patients maintained on methadone ( 25 to $45 \mathrm{mg} /$ day) (Jasinski et al. 1983) and was not consistently identified as an agonist or an antagonist in patients maintained on 30 $\mathrm{mg} /$ day of methadone (Strain et al. 1992). Because buprenorphine does not precipitate severe withdrawal, it appears to be useful for opiate detoxification (Bickel et al. 1988; Kosten and Kleber 1988).

The effects of buprenorphine-naloxone combinations have been studied in rats and monkeys, and pretreatment with naloxone usually blocks buprenorphine's effects. In squirrel monkeys (Saimiri sciureus), simultaneous administration of naloxone $(0.1$ to $1.0 \mathrm{mg} / \mathrm{kg}$, IM) and buprenorphine $(0.01$ to $0.10 \mathrm{mg} / \mathrm{kg}$ ) resulted in an attenuation of the decreased rates of food-maintained responding induced by buprenorphine alone (Dykstra 1983). Naloxone $(0.3 \mathrm{mg} / \mathrm{kg})$ antagonism of buprenorphine's rate-reducing effects was equivalent when naloxone was given simultaneously with or 15 minutes before buprenorphine administration (Dykstra 1983). Simultaneous naloxone $(1.0 \mathrm{mg} / \mathrm{kg})$ and buprenorphine administration antagonized the discriminative stimulus effects of buprenorphine in rats (Shannon et al. 1984). Concurrent administration of naloxone ( 0.1 $\mathrm{mg} / \mathrm{kg}$ and $1.0 \mathrm{mg} / \mathrm{kg}$ ) also antagonized the rate-decreasing effects of buprenorphine $(0.0001$ to $0.1 \mathrm{mg} / \mathrm{kg})$ on both punished and unpunished food-maintained responding in squirrel monkeys (DeRosett and Holtzman 1984). In rhesus monkeys that were not opioid dependent, combined administration of buprenorphine and naloxone maintained more avoidance-escape behavior than buprenorphine alone (Hoffmeister 1986).

In the present study, we compared the effects of simultaneous naltrexone and buprenorphine administration with the effects of pretreatment with the same ascending doses of naltrexone given 20 minutes before buprenorphine administration. The potential clinical 
utility of a buprenorphine-naltrexone combination would be greatest in a simultaneous administration paradigm. However, the profile of buprenorphine's receptor binding in relation to its pharmacologic effects is not well understood and the kinetic and binding profile of buprenorphine in the presence of naltrexone is unknown. Buprenorphine's agonist and antagonist actions appear to have a bell-shaped dose-response curve on several measures (Cowan et al. 1977; Lizasoain et al. 1991; Pechnick et al. 1985). Kinetic studies indicate that buprenorphine reaches peak plasma levels within 2 minutes after intravenous administration in man (Bullingham et al. 1980), within 2 to 5 minutes in baboon (Lloyd-Jones et al. 1980), and rapidly reaches peak levels in rodent and baboon brain within 10 to 15 minutes after administration (Holland et al. 1989; Shiue et al. 1991). Brain uptake studies with tracer doses of a fluorinated analogue of naltrexone [6-deoxy-6 $\beta$-fluoronaltrexone; cyclofoxy] indicate that near maximal brain uptake occurs within 20 minutes after administration (Kawai et al. 1990; Ostrowski et al. 1987; Sawada et al. 1991).

We also studied the effects of naltrexone given 20 minutes before buprenorphine on cocaine and foodmaintained responding. The 20 -minute naltrexone pretreatment procedure was used to ensure that naltrexone binding to the opiate receptors occurred before buprenorphine administration. We postulated that if buprenorphine's opioid agonist effects were important in reducing cocaine self-administration, the administration of naltrexone 20 minutes before buprenorphine would antagonize the partial mu agonist activity of buprenorphine. Alternatively, if buprenorphine's antagonist effects were important in reducing cocaine selfadministration, then simultaneous administration of naltrexone and buprenorphine might increase the antagonist effect of these compounds.

The effects of naltrexone given after buprenorphine were not studied because it is well established that opioid antagonists do not reverse buprenorphine's effects if buprenorphine is given first. For example, behavioral studies have shown that the discriminative stimulus effects of buprenorphine could not be reversed by naltrexone given 25 minutes after buprenorphine, but could be prevented by naltrexone pretreatment in pigeons (France et al. 1984). Similarly, administration of naloxone after buprenorphine did not antagonize buprenorphine's effects in a discrimination paradigm (Shannon et al. 1984) or on an analgesia measure in rats (Cowan et al. 1977). In clinical studies, naltrexone did not precipitate withdrawal signs or symptoms in buprenorphine-maintained patients as it did in methadone-maintained patients (Kosten et al. 1990).

\section{METHODS}

Five rhesus monkeys (Macaca mulatta) [one female and four males] were studied. Subjects weighed from 6.9 $\mathrm{kg}$ to $13.1 \mathrm{~kg}$ (average $10.3 \pm 1.05 \mathrm{~kg}$ ) and had a history of intravenous cocaine self-administration that averaged 599 days (range 44 to 1002 days) at the beginning of this study. Monkeys were maintained at ad libitum weight and given multiple vitamins, fresh fruit and vegetables, and Purina monkey chow to supplement a banana pellet diet. Food supplements were given between 5:00 PM and 5:30 PM. Water was continuously available. A 12-hour light-dark cycle was in effect from 7 AM to $7 \mathrm{PM}$, and the experimental chamber was dark during food and drug self-administration sessions.

Double-lumen silicone rubber catheters (inside diameter 0.028 inches, outside diameter 0.080 inches) were surgically implanted to facilitate pretreatment with saline, naltrexone, and buprenorphine (alone or in combination with naltrexone) and concurrent cocaine selfadministration. Catheters were implanted in the jugular or femoral vein and exited in the midscapular region. All surgical procedures were performed under aseptic conditions, and monkeys were anesthetized with either pentobarbital $(30 \mathrm{mg} / \mathrm{kg}$, IV) or ketamine $(25 \mathrm{mg} / \mathrm{kg}$, IM). After surgery, monkeys were given 200,000 units of Combiotic Dihydrostreptomycin and Penicillin G intramuscular every other day for a total of five injections. The intravenous catheter was protected by a tether system consisting of a custom-fitted nylon vest connected to a flexible stainless-steel cable and fluid swivel (Spaulding Medical Products, Birmingham, AL). This flexible tether system permits monkeys to move freely. Catheter patency was evaluated periodically by administration of a short-acting barbiturate, methohexital sodium ( $3 \mathrm{mg} / \mathrm{kg}, \mathrm{IV})$, through the catheter.

Animal maintenance and research was conducted in accordance with the guidelines provided by the Committee on Laboratory Animal Resources. The facility is licensed by the U.S. Department of Agriculture, and protocols were approved by the Institutional Animal Care and Use Committee. The health of the monkeys was periodically monitored by consultant veterinarians trained in primate medicine. Operant food and drug acquisition procedures provided an opportunity for environmental manipulation and enrichment (Line 1987; Line et al. 1989). Monkeys had visual, auditory, and olfactory contact with other monkeys throughout the study.

\section{Sequence of Treatment Conditions}

Effects of Simultaneous Buprenorphine-Naltrexone Combinations on Cocaine and Food Self-Administration (Study I). The goal of this study was to examine the effects of concurrent treatment with buprenorphine and naltrexone on cocaine and food self-administration. Buprenorphine alone $(0.40 \mathrm{mg} / \mathrm{kg} /$ day $)$ and in combination with ascending doses of naltrexone $(0.05,0.10$, 0.20 , and $0.40 \mathrm{mg} / \mathrm{kg} /$ day) were compared with naltrexone alone $(0.40 \mathrm{mg} / \mathrm{kg} /$ day $)$ and saline control treat- 
ment. The sequence of pretreatment conditions was as follows: (1) saline alone, (2) buprenorphine alone, (3) saline alone, (4 to 7) four combinations of buprenorphine and naltrexone, and (8) naltrexone alone. Each of the eight treatment conditions was in effect for 10 days. This buprenorphine dose $(0.40 \mathrm{mg} / \mathrm{kg} /$ day $)$ was within the range of doses that significantly reduced cocaine self-administration in our previous studies (Mello et al. 1989, 1990, 1992a).

Effects of Naltrexone Pretreatment on Buprenorphine's Effects on Cocaine and Food Self-Administration (Study

II). Subsequently, the same four ascending doses of naltrexone $(0.05$ to $0.40 \mathrm{mg} / \mathrm{kg} /$ day $)$ were administered 20 minutes before buprenorphine $(0.40 \mathrm{mg} / \mathrm{kg} /$ day $)$ and followed by a saline-only control treatment. Each of thesefive treatment conditions was in effect for 10 days. The 20-minute naltrexone pretreatment interval was used to ensure that there was sufficient time for naltrexone to bind to the opioid receptors before buprenorphine was administered (Kawai et al. 1990; Ostrowski et al. 1987; Sawada et al. 1991). Each treatment condition was in effect for 10 days.

\section{Administration of Buprenorphine, Naltrexone or Saline Solutions}

In Study I, buprenorphine, naltrexone, and buprenorphine-naltrexone combinations or an equal volume of saline control solution was administered as a slow injection between 9:30 and 10:30 AM. In Study II, ascending doses of naltrexone $(0.05$ to $0.40 \mathrm{mg} / \mathrm{kg} /$ day $)$ were administered 20 minutes before buprenorphine $(0.40$ $\mathrm{mg} / \mathrm{kg} /$ day) administration. Each solution was slowly injected at a rate of $1 \mathrm{ml}$ of solution every 10 minutes over a 50-minute period and flushed through with sterile saline in a volume that exceeded the estimated catheter dead space. This buprenorphine, naltrexone, and saline administration procedure was identical to that used in each of our previous studies (Mello et al. 1989, 1990, 1992a). Each treatment solution was infused through the second lumen of the double-lumen catheter. Both catheter lumens remained patent throughout the study.

\section{Operant Behavioral Procedures and Apparatus}

Monkeys worked at an operant task for food and intravenous cocaine injections in a well-ventilated chamber equipped with an operant panel, a pellet feeder, and a water dispenser. Drug injections were delivered by a syringe pump in a single pulse that dispensed $0.1 \mathrm{ml}$ of fluid over a 0.9 -second period. The operation of the syringe pump (Model 981210; Harvard Apparatus, Inc., South Natick, MA) was audible to the monkey. Schedules of reinforcement were programmed by custom- designed software and run on Apple IIGS microcom. puters.

Cocaine self-administration was studied at the dose that maintained the highest response rates during train. ing. All monkeys self-administered $0.05 \mathrm{mg} / \mathrm{kg}$ per injection of cocaine throughout this study. Food ( $1 \mathrm{gm}$ banana pellet) and cocaine $(0.05 \mathrm{mg} / \mathrm{kg}$ per injection) self-administration were maintained on a second-order schedule of reinforcement [fixed ratio 4 (FR 4) variable ratio (VR) 16:S]. An average of 16 responses on a VR 16 schedule produced a brief colored stimulus light $(S+)$. However, a drug injection or a food pellet was delivered only after an FR 4 of the VR 16 response requirements had been completed; that is, each food pel. let or drug injection required an average of 64 responses. These procedures were identical to those previously used in our studies of daily buprenorphine treatment (Mello et al. 1989, 1990, 1992a).

The conditions of food and cocaine availability were each associated with a different colored stimulus light $(\mathrm{S}+)$ projected on a translucent Plexiglas response key ( 2 inches in diameter) in the center of the operant panel. No stimulus lights $(\mathrm{S}+)$ were illuminated during timeout periods (when responses had no programmed consequence). When a food pellet or drug injection was delivered, the appropriate colored stimulus light $(\mathrm{S}+)$ (red or green) was illuminated for 1 second on 3 circles (3/4 inches in diameter) located in a vertical column below the response key. These 1-second colored stimulus light flashes $(\mathrm{S}+)$ also signaled the completion of each successive component of the second-order schedule response requirement.

Each experimental day began at 9:00 AM and consisted of four food and four drug availability sessions. Food sessions began at 11:00 AM, 3:00 PM, 7:00 PM, and 7:00 AM each day and drug sessions began 1 hour later at 12 noon, 4:00 PM, 8:00 PM, and 8:00 AM. Each food or drug session lasted for 1 hour or until 100 food pellets or 20 drug injections had been delivered. Cocaine injections were limited to 80 per day to minimize the possibility of adverse drug effects. A time-out period when responses have no programmed consequences occurs between successive drug and food sessions.

\section{Drug Solution Preparation}

Buprenorphine. Buprenorphine hydrochloride was obtained from the National Institute on Drug Abuse (NIDA). Buprenorphine was dissolved in sterile water at a concentration of 8.0 or $16.7 \mathrm{mg} / \mathrm{ml}$. The stock solution was then filter sterilized using a $0.22-\mu$ filter and stored in sterile, pyrogen-free vials. Solutions were checked daily to ensure that no precipitate had formed. Fresh solutions were prepared every 14 to 21 days. Doses were calculated on the basis of the monkeys' weights so that a final dilution of stock solution (with 
sterile saline for injection, U.S.P.) resulted in a daily infusion of each buprenorphine dose in a volume of 5.0 $\mathrm{ml}$ per infusion.

Naltrexone. Naltrexone was obtained from NIDA. Stock solutions were prepared by dissolving naltrexone in sterile saline for injection, U.S.P. The solution was then filter sterilized using a $0.22-\mu$ filter and stored in sterile, pyrogen-free vials. Doses were calculated on the basis of each monkey's weight so that a final dilution yielded a unit dose of 0.32 or $3.20 \mathrm{mg} / \mathrm{kg}$ per injection in a volume of $5.0 \mathrm{ml}$ per injection per day.

Cocaine. Cocaine hydrochloride was obtained in crystalline form from NIDA. The purity was certified by Research Triangle Institute to be greater than $98 \%$. Cocaine was dissolved in sterile saline for injection, U.S.P. to make a stock solution at a concentration of $50 \mathrm{mg} / \mathrm{ml}$. The solution was then filter sterilized using a $0.22-\mu$ Millipore filter and stored in sterile, pyrogen-free vials. Doses were calculated on the basis of monkeys' weights so that a final dilution of the stock solution (with sterile saline for injection, U.S.P.) resulted in a unit dose of $0.05 \mathrm{mg} / \mathrm{kg}$ per injection in a volume of $0.1 \mathrm{ml} /$ injection.

\section{Data Analysis}

Buprenorphine's effects on cocaine- and food-maintained responding were evaluated with one-way analysis of variance (ANOVA) for repeated measures. The number of cocaine injections and food pellets acquired during the saline treatment baseline was compared with 10-day periods when buprenorphine only, naltrexone only,

combinations were administered (Study I) and with 10day periods when naltrexone was administered 20 minutes before buprenorphine (Study II). The effects of simultaneous buprenorphine and naltrexone treatment were also compared with conditions in which the same doses of naltrexone $(0.05$ to $0.40 \mathrm{mg} / \mathrm{kg} /$ day $)$ were given 20 minutes before buprenorphine. If the ANOVA showed a significant main effect, Dunnett's Multiple Comparison Procedure was used to determine which conditions were significantly different from the saline treatment baseline or from the effects of buprenorphine alone. To determine if the effects of naltrexone on cocaine self-administration were naltrexone dose dependent, ANOVAs with naltrexone as a repeated measure were run for the simultaneous and for the 20-minute pretreatment conditions. Degrees of freedom were corrected using Geisser-Greenhouse Epsilon factors. When repeated-measures ANOVAs yielded significant effects, linear contrasts were evaluated comparing control conditions to all treatment conditions. Probability levels of $p<.05$ to .0001 are reported as statistically significant. In some instances, data are expressed as the average percent change from each subject's saline treatment baseline to facilitate comparisons between monkeys.

\section{RESULTS}

\section{Buprenorphine's Effects on Cocaine Self-Administration}

Buprenorphine significantly reduced cocaine self-administration in comparison to saline treatment $(p<.01)$. Group data for five monkeys are shown in Figure 1. During saline treatment, monkeys self-administered an average of $65.5( \pm 5.8)$ cocaine injections per day. Cocaine self-administration fell to 27.9 ( \pm 7.6$)$ injections per day during buprenorphine treatment and then returned to baseline levels of $62.3( \pm 3.6)$ injections per day when saline treatment was resumed (Fig. 1, left panel). This rapid increase in cocaine self-administration probably reflects the relatively short duration of buprenorphine treatment, because recovery was slower after 30 to 120 days of buprenorphine treatment (Mello et al. 1990, 1992a).

\section{Simultaneous Naltrexone and Buprenorphine Administration: Effects on Cocaine Self-Administration (Study I)}

When ascending doses of naltrexone (0.05 to 0.40 $\mathrm{mg} / \mathrm{kg} /$ day) were given simultaneously with buprenorphine in a single solution, cocaine self-administration remained significantly below the saline treatment baseline $(p<.05$ to .01$)$. Group data $(n=5)$ are shown in the center panel of Figure 1. The magnitude of the reduction in cocaine self-administration was significantly less $(p<.05$ to .01$)$ during treatment with the four naltrexone and buprenorphine combinations than during treatment with buprenorphine alone. However, the effects of simultaneous buprenorphine and naltrexone administration were not naltrexone dose dependent. Naltrexone alone had no effect on cocainemaintained responding. Average cocaine injections per day during naltrexone treatment were equivalent to cocaine self-administration during saline treatment (63.2 \pm 5.3 vs. $65.5 \pm 5.8$ )

Cocaine self-administration data for the group $(n=$ 5) expressed as percent change from the initial saline treatment baseline are shown in Figure 2 (left panel). Buprenorphine alone reduced cocaine self-administration by $53 \%$ but ascending doses of naltrexone in combination with the same dose of buprenorphine reduced cocaine self-administration by only $30 \%, 30 \%$, $23 \%$, and $23 \%$, respectively (Fig. 2, left). Cocaine selfadministration during buprenorphine treatment alone was significantly less $(p<.05$ to .01$)$ than during simultaneous buprenorphine plus naltrexone treatment. 


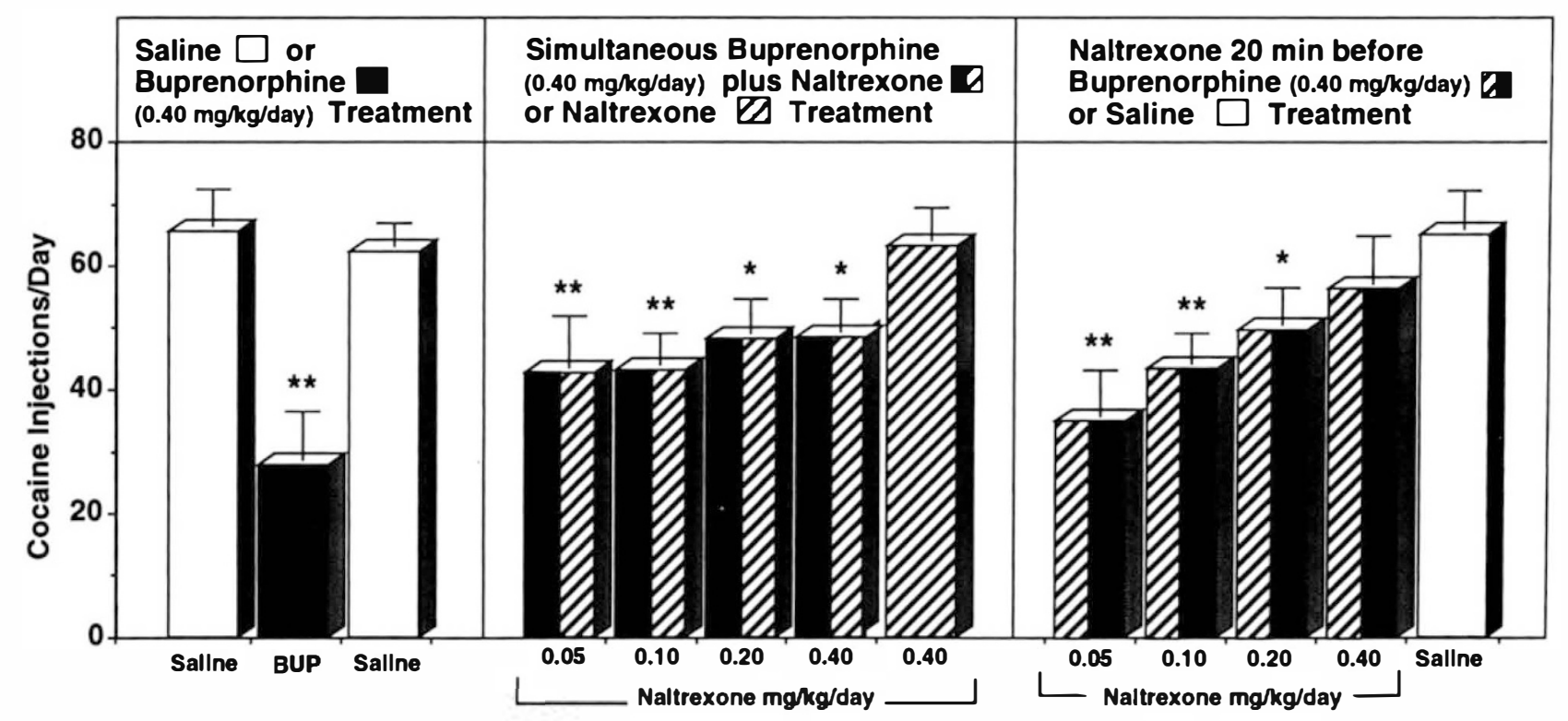

Consecutive 10 day Averages ( \pm SEM)

Figure 1. Effects of buprenorphine or naltrexone only, buprenorphine-naltrexone combinations, and saline control treatment on cocaine self-administration. Group data for five monkeys are shown in each 10-day treatment condition. Cocaine injections per day $(\bar{x} \pm S E)$ are shown on the left ordinate. Cocaine self-administration during daily saline (open bar) and $0.40 \mathrm{mg} / \mathrm{kg}$ buprenorphine (black bar) treatment are shown in the left panel. Cocaine self-administration during simultaneous administration of buprenorphine and ascending doses of naltrexone ( 0.05 to $0.40 \mathrm{mg} / \mathrm{kg})$ (black and striped bars) and naltrexone alone (striped bar) are shown in the middle panel. Cocaine self-administration during treatment with ascending doses of naltrexone $(0.05$ to $0.40 \mathrm{mg} / \mathrm{kg} /$ day $)$ administered 20 minutes before buprenorphine $(0.40 \mathrm{mg} / \mathrm{kg}$ day) (striped and black bars) and during saline control treatment (open bar) are shown in the right panel. Asterisks indicate statistically significant changes from the prebuprenorphine saline baseline treatment as determined by ANOVA for repeated measures and Dunnett's follow-up tests $\left({ }^{*} p<.05 ;{ }^{\star \star} p<.01\right)$.

\section{Effects of Naltrexone Pretreatment on Buprenorphine's Effects on Cocaine Self-Administration (Study II)}

Administration of naltrexone 20 minutes before buprenorphine resulted in a significant naltrexone dosedependent attenuation of buprenorphine's reduction of cocaine self-administration $(p<.01)$. Cocaine selfadministration remained significantly lower than the initial saline treatment baseline at naltrexone doses of 0.05 to $0.20 \mathrm{mg} / \mathrm{kg} /$ day in combination with buprenorphine (Fig. 1, right panel). But at the highest dose of naltrexone $(0.40 \mathrm{mg} / \mathrm{kg} /$ day $)$ and buprenorphine, cocaine self-administration was not significantly lower than during the first saline treatment baseline condition (Fig. 1). Cocaine self-administration during the third saline treatment condition also did not differ significantly from the initial saline baseline (Fig. 1).

In comparison to buprenorphine treatment alone (53\% reduction), there was an orderly naltrexone dosedependent decrease in buprenorphine's reduction of cocaine self-administration from $42 \%$ to $31 \%$ to $19 \%$ to $8 \%$, respectively, below the saline treatment baseline. Cocaine self-administration was significantly higher during treatment with naltrexone doses of $0.10,0.20$, and $0.40 \mathrm{mg} / \mathrm{kg}$ in combination with buprenorphine than during buprenorphine alone $(p<.05$ to .01$)$ (Fig. 2 , right panel). Cocaine self-administration during pretreatment with the lowest dose of naltrexone plus buprenorphine did not differ from buprenorphine alone (Fig. 2, right panel).

\section{Buprenorphine's Effects on Food Self-Administration}

Food self-administration decreased from $91.7 \pm 14$ to $67.2 \pm 9$ pellets per day during buprenorphine treatment, but this change $(26.7 \%)$ was not statistically significant. When saline was substituted for buprenorphine, food self-administration returned to control levels of $95.7 \pm 11$ pellets per day. Food self-administration during saline and buprenorphine treatment is shown in Figure 3 (left panel).

\section{Simultaneous Naltrexone and Buprenorphine Administration: Effects on Food Self-Administration (Study I)}

Food self-administration during simultaneous buprenorphine and naltrexone administration did not differ significantly from either the saline treatment baseline 


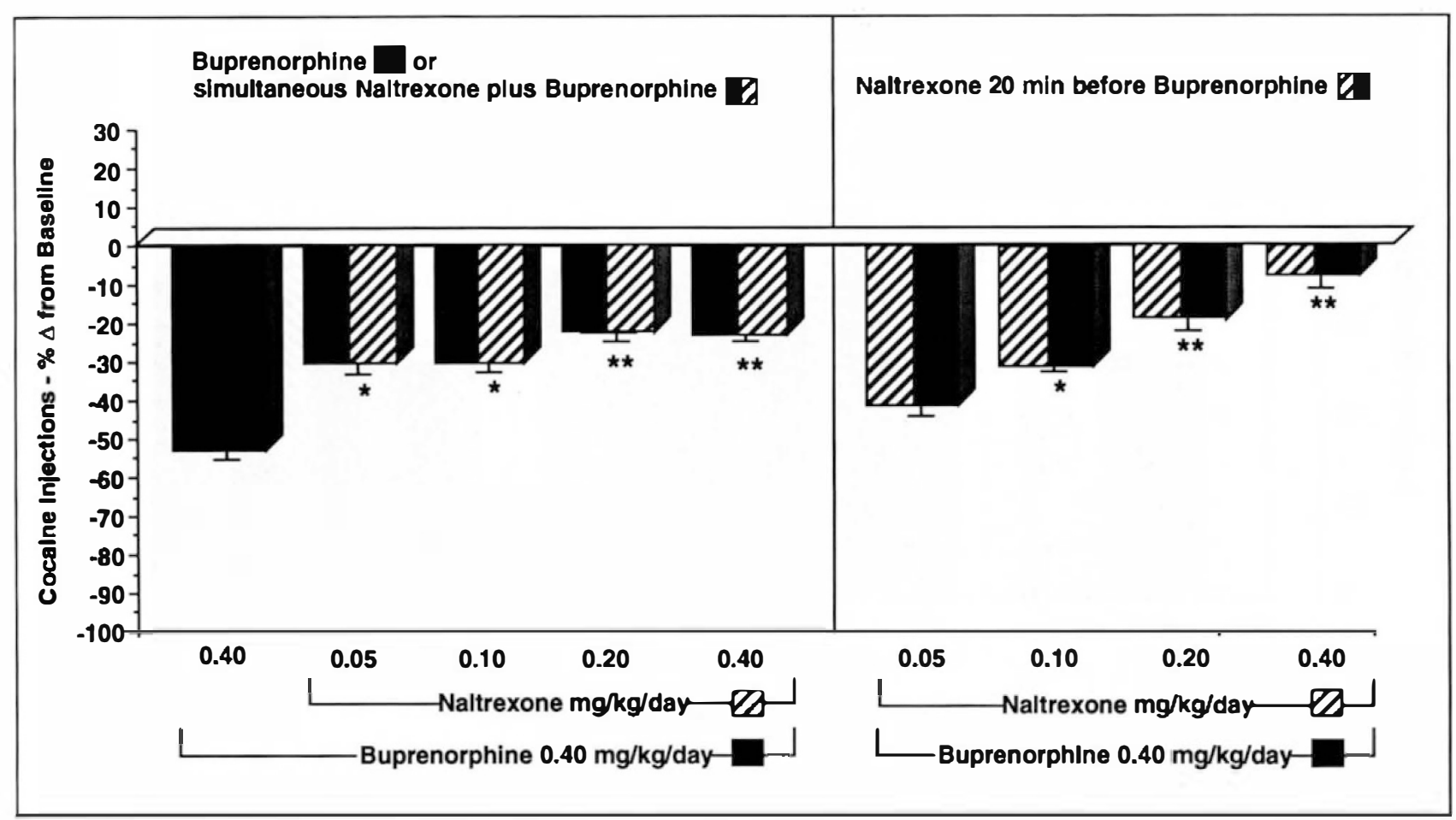

Figure 2. Comparison of the effects of buprenorphine only with buprenorphine-naltrexone combinations on cocaine selfadministration. The average number of cocaine injections $(\bar{x} \pm \mathrm{SE})$ self-administered by five monkeys during successive 10-day treatment conditions are shown as percent change from the prebuprenorphine saline treatment baseline. Percent change from baseline is shown on the left ordinate. Successive 10-day periods of buprenorphine treatment (black bar), buprenorphine and simultaneous administration of ascending doses of naltrexone ( 0.05 to $0.40 \mathrm{mg} / \mathrm{kg} / \mathrm{day})$ (black and striped bars) are shown in the left panel. Successive 10 -day periods of ascending doses of naltrexone $(0.05$ to $0.40 \mathrm{mg} / \mathrm{kg} / \mathrm{day}) \mathrm{administered}$ 20 minutes before buprenorphine (striped and black bars) are shown in the right panel. The statistical significance of changes in cocaine self-administration during combined naltrexone-buprenorphine treatment in comparison to buprenorphine treatment alone are shown as asterisks $\left({ }^{\star} p<.05 ;{ }^{\star *} p<.01\right)$.

or buprenorphine treatment alone. Food self-administration was somewhat variable during this condition and showed no orderly relation to the ascending doses of naltrexone. Group data $(n=5)$ are shown in the center panel of Figure 3.

\section{Effects of Naltrexone Pretreatment on Buprenorphine's Effects on Food Self-Administration (Study II)}

Food self-administration did not differ significantly from the saline treatment baseline throughout the 20minute naltrexone pretreatment plus buprenorphine condition (Fig. 3, right panel). However, there was a naltrexone dose-dependent increase in food selfadministration that paralleled the increase in cocaine self-administration (Figs. 1 and 3, right panels). When cocaine self-administration increased further during the final saline treatment condition (Fig. 1), food selfadministration returned to initial saline treatment levels (Fig. 3).

\section{Individual Patterns of Cocaine Self-Administration During Buprenorphine and Naltrexone Treatment}

Daily cocaine self-administration by individual monkeys during treatment with buprenorphine only, naltrexone only, and simultaneous administration of buprenorphine and naltrexone $(0.40 \mathrm{mg} / \mathrm{kg} /$ day $)$ are shown in figure 4 . Data are shown as percent change from each monkey's saline treatment baseline to facilitate comparisons between subjects. The time course and degree of reduction in cocaine-maintained responding varied across individuals. Buprenorphine treatment was followed by an abrupt and sustained reduction in cocaine self-administration in four monkeys (Fig. 4, rows 1 to 4 ). Over the 10 days of buprenorphine treatment, their cocaine self-administration was reduced by an average of $96 \%, 75 \%, 42 \%$, and $35 \%$, respectively. One monkey was relatively insensitive to buprenorphine treatment, and cocaine self-administration averaged only $20 \%$ below baseline (Fig. 4, row 5 ). In contrast to buprenorphine, naltrexone alone re- 


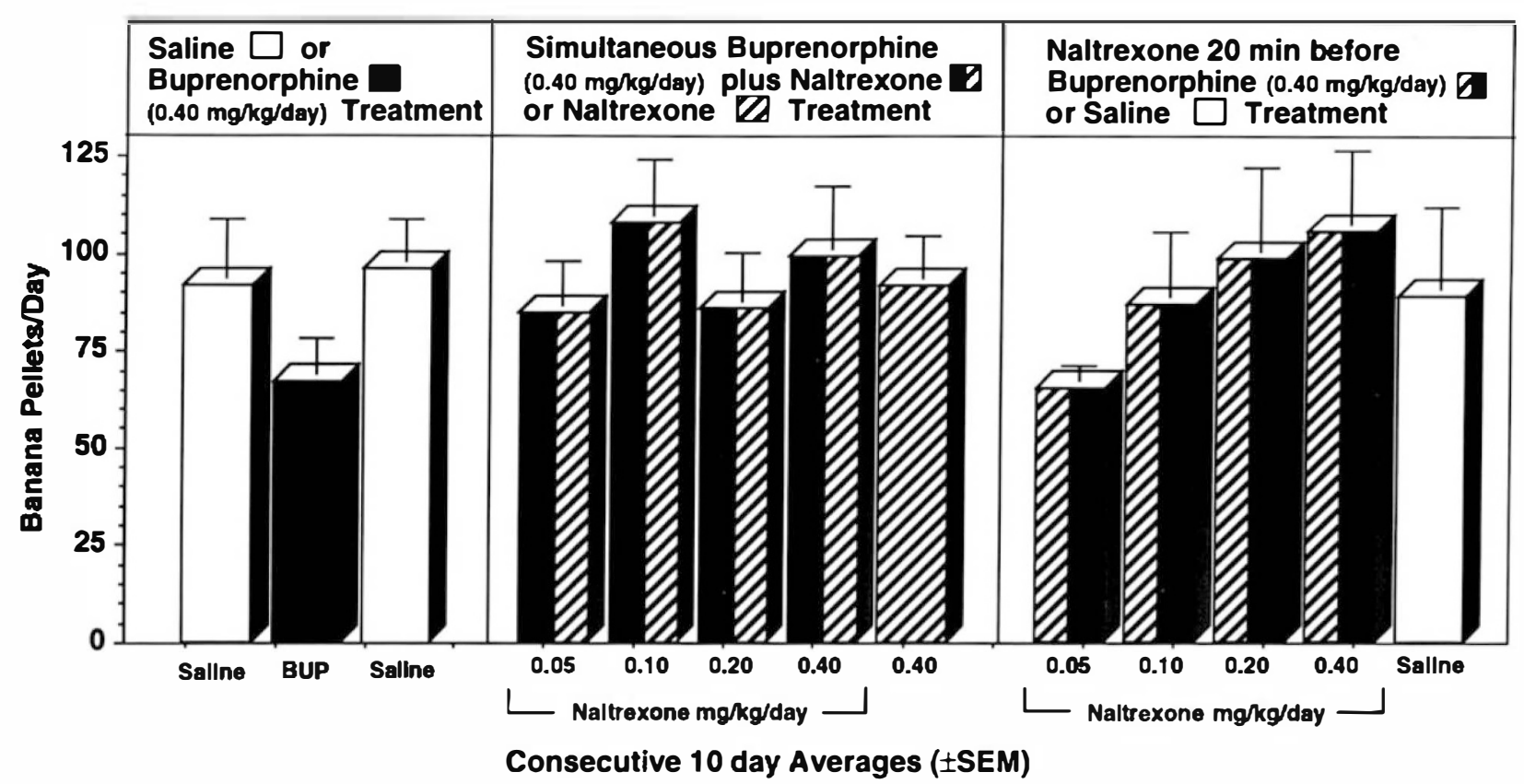

Figure 3. Effects of buprenorphine or naltrexone only, buprenorphine-naltrexone combinations, and saline control treatment on food self-administration. Group data for five monkeys are shown in each 10-day treatment condition. Food pellets per day $(\bar{x} \pm S E)$ are shown on the left ordinate. Food self-administration during daily saline (open bar) and buprenorphine $(0.40 \mathrm{mg} / \mathrm{kg})$ (black bar) treatment are shown in the left panel. Food self-administration during simultaneous administration of buprenorphine and ascending doses of naltrexone $(0.05$ to $0.40 \mathrm{mg} / \mathrm{kg}$ ) (black and striped bars), and naltrexone only (striped bar) are shown in the middle panel. Food self-administration during treatment with ascending doses of naltrexone (0.05 to $0.40 \mathrm{mg} / \mathrm{kg} /$ day) administered 20 minutes before buprenorphine $(0.40 \mathrm{mg} / \mathrm{kg} /$ day) (striped and black bars) and during saline control treatment (open bar) are shown in the right panel.

duced cocaine self-administration by an average of $25 \%$ in only one monkey (Fig. 4, row 2). The other four monkeys' cocaine self-administration remained similar to their respective saline baselines during naltrexone treatment (range $7 \%$ to $10 \%$ below baseline). When the same doses of naltrexone and buprenorphine were administered simultaneously, cocaine self-administration was lower than during naltrexone treatment alone but higher than during buprenorphine treatment alone in all monkeys (Fig. 4, rows 1 to 4$)$. The average reduction in cocaine self-administration over 10 days from the previous saline treatment baseline ranged from less than $1 \%$ (Fig. 4, row 3 ) to $59 \%$ (Fig. 4, row 2). The effectiveness of the buprenorphine-naltrexone combination in reducing cocaine self-administration increased over time in three monkeys (Fig. 4, rows 1, 2, and 4) and remained relatively stable in two monkeys (Fig. 4 , rows 3 and 5).

\section{DISCUSSION}

\section{Effects of Buprenorphine and Buprenorphine-Naltrexone Combinations on Cocaine Self-Administration}

Buprenorphine alone $(0.40 \mathrm{mg} / \mathrm{kg} /$ day $)$ signifıcantly reduced cocaine self-administration by rhesus mon- keys by an average of $53 \%$ in comparison to saline control treatment $(p<0.1)$. These data confirm and extend previous findings in the primate and rodent drug selfadministration model (Carroll et al. 1992; Carroll and Lac 1992; Mello et al. 1989, 1990, 1992a). However, concurrent administration of naltrexone and buprenorphine significantly reduced the effects of buprenorphine alone on cocaine self-administration (Figs. 1 and 2). Simultaneous administration of ascending doses of naltrexone $(0.05$ to $0.40 \mathrm{mg} / \mathrm{kg} /$ day $)$ signifcantly reduced the suppressive effects of buprenorphine treatment on cocaine self-administration $(p<.05$ to .01), but this effect was equivalent across the naltrexone doses studied. Naltrexone alone had no effect on cocaine-maintained responding. When naltrexone was given 20 minutes before buprenorphine, there was a significant naltrexone dose-dependent attenuation of buprenorphine's effects on cocaine self-administration ( $p<.05$ to .01$)$ (Figs. 1 and 2).

Because the opioid antagonist, naltrexone, has selective activity at the mu receptor (France et al. 1990; Martin et al. 1973) and buprenorphine is a partial mu agonist (Jaffe and Martin, 1990), these data suggest that naltrexone antagonized the mu agonist component of buprenorphine and this, in turn, attenuated buprenorphine's effectiveness in reducing cocaine self-administration in monkey. These data are consis- 


\section{Cocaine Self-Administration}
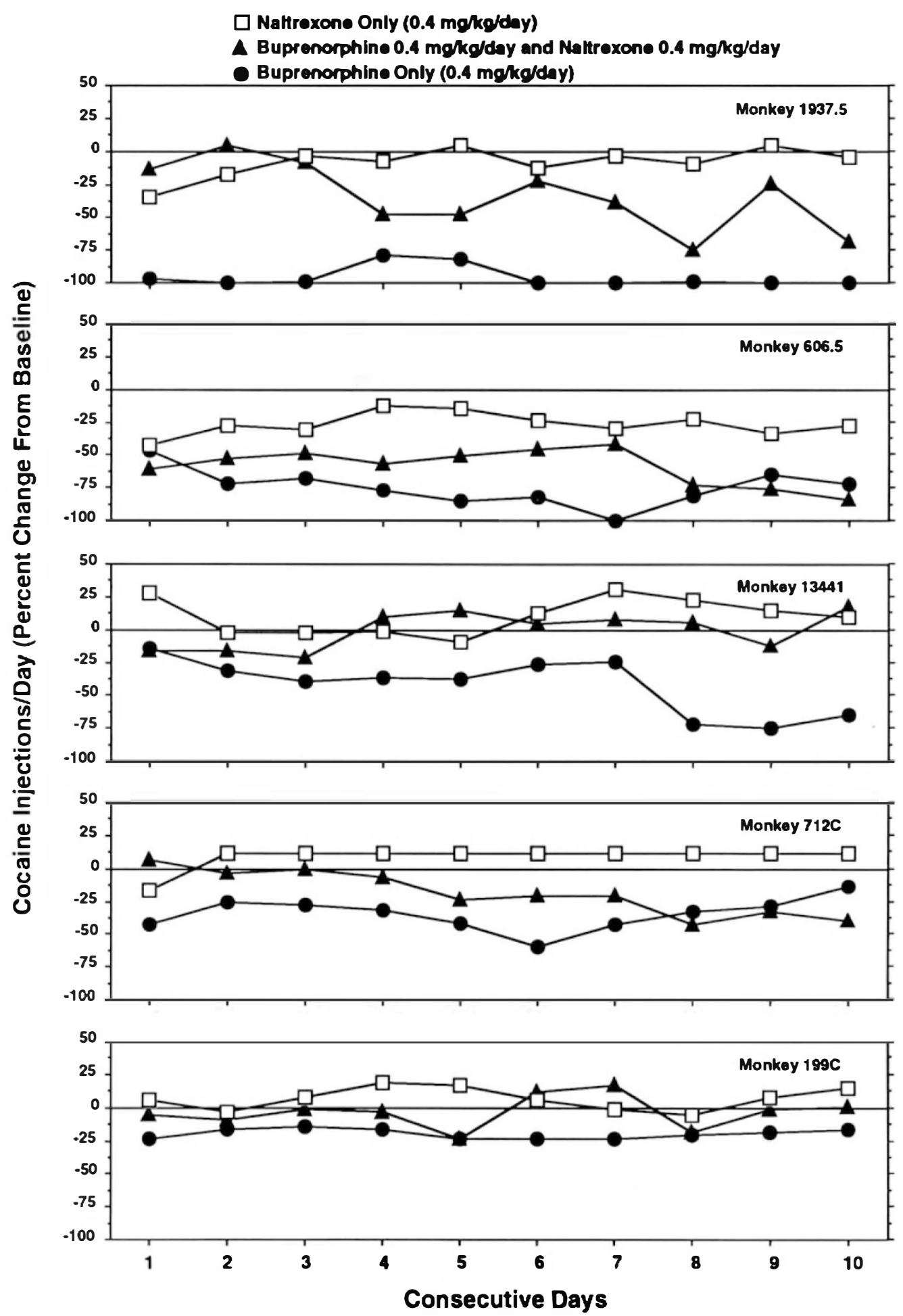

Figure 4. Time course of changes in cocaine self-administration during treatment with buprenorphine only $(0.40 \mathrm{mg} / \mathrm{kg} / \mathrm{day})$, naltrexone only $(0.40 \mathrm{mg} / \mathrm{kg} /$ day $)$, and simultaneous administration of buprenorphine $(0.40 \mathrm{mg} / \mathrm{kg} /$ day $)$ and naltrexone $(0.40$ $\mathrm{mg} / \mathrm{kg} /$ day). Daily cocaine self-administration during buprenorphine treatment (black circles), naltrexone treatment (open squares), and simultaneous administration of buprenorphine and naltrexone $(0.40 \mathrm{mg} / \mathrm{kg} /$ day) (closed triangles) are shown for individual monkeys. Data are expressed as percent change in cocaine injections from the saline treatment baseline (left ordinate) over 10 consecutive days (abscissa). 
tent with recent findings that naltrexone ( 0.3 to 1.0 $\mathrm{mg} / \mathrm{kg}$ ) antagonized the protective effects of buprenorphine in reducing lethality associated with cocaineinduced convulsions in mice (Witkin et al. 1991). The opioid agonists, morphine and methadone, also reduced cocaine-related lethality in mice, whereas naltrexone alone did not (Witkin et al. 1991). These data were interpreted to suggest that buprenorphine's protective effects were mediated by mu opioid receptors (Witkin et al. 1991).

In rhesus monkey, acute administration of either an opioid agonist, (heroin, 0.03 and $0.10 \mathrm{mg} / \mathrm{kg}$ ) or buprenorphine (1.0 and $3.2 \mathrm{mg} / \mathrm{kg}$ ) suppressed rates of cocaine-maintained responding over the dose range of 0.001 to $0.1 \mathrm{mg} / \mathrm{kg}$ per injection of cocaine (Winger et al. 1992). These data could be interpreted to suggest that buprenorphine was acting like a mu agonist in that paradigm. Yet, quadazocine, an opioid antagonist, produced equivalent suppression of cocainemaintained responding at doses of 0.1 and $1.0 \mathrm{mg} / \mathrm{kg}$, which was interpreted as probably not due to its opioid antagonist actions (Winger et al. 1992). Because the effects of heroin, buprenorphine, and quadazocine on concurrent food-maintained responding were not studied by Winger and coworkers, the selectivity of these drug effects for cocaine cannot be established with certainty.

If the mu opioid agonist component of buprenorphine is one important factor in its interactions with cocaine, then treatment with an opioid agonist such as methadone should also be effective in reducing cocaine self-administration. However, clinical reports indicate that methadone was less effective than buprenorphine or naltrexone in reducing cocaine abuse by opiate-dependent patients (Kosten et al. 1989a, 1989b). In other studies of opiate-dependent patients, intermittent cocaine use continued during treatment with either methadone or buprenorphine (Fudala et al. 1991; Johnson et al. 1992). Moreover, cocaine's acute subjective effects and heart rate increases were greater in polydrug users on methadone maintenance $(50 \mathrm{mg} /$ day) than in abstinent opioid abusers (Preston et al. 1993). Preclinical studies of the effects of opioid agonists on cocaine self-administration by monkeys are also inconsistent; both no effect (Stretch 1977) and decreased cocaine self-administration have been reported (Wilson and Schuster 1970; Winger et al. 1992).

Whatever the role of mu opioid agonist activity in buprenorphine-cocaine interactions, there is increasing evidence that cocaine per se directly affects $\mathrm{mu}$ opioid receptors in the brain. Chronic cocaine exposure increases opiate receptor density in rodent brain (Hammer 1989; Ishizuka et al. 1988; Unterwald et al. 1992). Increased opiate receptor density in brain areas associated with drug reinforcement was inferred from observed changes in binding of $\left[{ }^{3} \mathrm{H}\right]$ naloxone (Hammer 1989; Ishizuka et al. 1988) and a mu-selective opioid ligand [ $\left.{ }^{3} \mathrm{H}\right] \mathrm{DSAMGO}$ (Unterwald et al. 1992). Evidence of cocaine-induced increases in opioid receptor density in brain raises the intriguing possibility that the duration of cocaine exposure and/or the degree of cocaine dependence may influence buprenorphine's effectiveness in reducing cocaine self-administration. This notion is supported by the finding that although buprenorphine ( $4 \mathrm{mg} /$ day) significantly reduced cocaine self-administration by patients who met DSM-III-R criteria for dependence on cocaine as well as opiates and had abused both drugs for over 10 years (Gastfriend et al. 1992, 1993a, 1993b), both buprenorphine and methadone were equally ineffective in reducing cocaine intake in nondependent, intermittent cocaine abusers (Fudala et al. 1991; Johnson et al. 1992). Because cocaine's reinforcing and discriminative stimulus properties appear to reflect inhibition of dopamine reuptake (Johanson and Fischman 1989; Kuhar et al. 1988), buprenorphine's interactions with both endogenous opioid and dopaminergic systems are probably important for its effects on cocaine selfadministration. It was neuroendocrine evidence of dopamine-opioid interactions that originally prompted us to explore buprenorphine's effects on cocaine self-administration (Mello and Mendelson 1993a, 1993b; Mello et al. 1989). The complexity of these interactions is itlustrated by reports that buprenorphine increases dopamine release in rat nucleus accumbens (Brown et al. $1991)$ and naltrexone $(1.0 \mathrm{mg} / \mathrm{kg})$ pretreatment prevents buprenorphine $(0.1 \mathrm{mg} / \mathrm{kg})$ induced dopamine release in the nucleus accumbens (Holman et al. 1993).

\section{Effects of Naltrexone on Cocaine and Food Self-Administration}

The failure of naltrexone $(0.40 \mathrm{mg} / \mathrm{kg})$ alone to affect cocaine self-administration is not consistent with previous clinical reports (Kosten et al. 1989a) or with our previous studies in rhesus monkey (Mello et al. 1990). Naltrexone significantly reduced cocaine-positive urines in heroin-dependent polydrug abusers (Kosten et al. 1989a) and reduced cocaine selfadministration by rhesus monkeys by $25 \%$ to $27 \%$ (Mello et al. 1990). Our previous studies were conducted under identical behavioral conditions, and the doses of naltrexone $(0.32$ to $3.20 \mathrm{mg} / \mathrm{kg} /$ day) overlapped the dose used in the present study $(0.40$ $\mathrm{mg} / \mathrm{kg} /$ day) (Mello et al. 1990). However, monkeys had a different sequence of exposure to treatment conditions. In our previous studies, naltrexone was administered after 15 days of saline treatment (Mello et al. 1990), whereas in this study, naltrexone treatment followed 40 days of treatment with buprenorphine and naltrexone combinations. Only one monkey 
(199C) was a subject in both studies. Naltrexone $(0.32$ $\mathrm{mg} / \mathrm{kg} /$ day) significantly decreased cocaine selfadministration $(p<.01)$ after 10 days of treatment (during days 11 to 15 ) in this monkey in our previous study (Mello et al. 1990), but cocaine self-administration was minimally affected by naltrexone $(0.40 \mathrm{mg} / \mathrm{kg} /$ day $)$ in the present study (see Fig. 4). The difference in naltrexone's effects in our two studies may be attributable, in part, to persistent effects of buprenorphine after 40 days of exposure. These data also underscore the importance of drug history and behavioral history in influencing responsivity to naltrexone (Warren and Morse 1989).

Naltrexone did not change food-maintained responding in comparison to the initial saline treatment baseline (Fig. 3). Naltrexone pretreatment was followed by a dose-dependent increase in food selfadministration that paralleled an increase in cocainemaintained responding (Figs. 1 and 3 ). In contrast to previous studies in squirrel monkeys (Goldberg et al. 1981), there was no evidence of excessive salivation or vomiting during 10 days of naltrexone treatment or 40 days of combined naltrexone and buprenorphine treatment in the present study or in our previous studies (Mello et al. 1990). In squirrel monkey, acute naltrexone administration $(10 \mathrm{mg} / \mathrm{kg})$ produced salivation and vomiting and after chronic daily naltrexone treatment for 38 to 39 days, supersensitivity to naltrexone developed and a lower dose $(0.3 \mathrm{mg} / \mathrm{kg})$ also produced vomiting (Goldberg et al. 1981). These discrepant findings may reflect differences in the naltrexone doses studied (10 mg/kg vs. $0.40 \mathrm{mg} / \mathrm{kg}$ ) as well as unexplained species differences.

\section{Buprenorphine-Cocaine Interactions}

We have suggested that buprenorphine's unique combination of agonist and antagonist characteristics is essential for its selective effects on cocaine selfadministration (Mello et al. 1993a; Mello and Mendelson 1993a, 1993b). Other opioid mixed agonist-antagonist analgesics such as nalbuphine and butorphanol also produce dose-dependent decreases in cocaine self-administration by rhesus monkeys (Mello et al. 1993b; Winger et al. 1992). However, these effects of chronic butorphanol and nalbuphine treatment over 10 days were not selective for cocaine because foodmaintained responding also decreased in parallel with cocaine self-administration (Mello et al. 1993a).

Although data described in this study suggest that the muagonistcomponent of buprenorphine is important for its interactions with cocaine, the mechanisms by which buprenorphine reduces cocaine self-administration are unknown. There is also compelling behavioral and physiologic evidence that buprenorphine has kappa antagonist effects in addition to its partial $\mathrm{mu}$ agonist properties. In behavioral studies, buprenorphine antagonized the effects of a selective kappa agonist, U50,488 (Negus and Dykstra 1988; Negus et al. 1990, 1991). Buprenorphine also precipitated withdrawal in kappa agonist-dependent monkeys (Gmerek et al. 1987) and antagonized the diuretic effects of a kappa agonist, bremazocine (Leander 1987; Richards and Sadee 1985). The extent to which buprenorphine's kappa antagonist effects may also contribute to its suppressive effects on cocaine self-administration remains to be determined once systemically active selective kappa antagonists become available.

\section{Clinical Implications}

Because the simultaneous administration of buprenorphine and naltrexone significantly reduced the suppression of cocaine self-administration achieved with buprenorphine alone (Figs. 1 and 2), the addition of an opioid antagonist to reduce illicit diversion of buprenorphine might compromise its effectiveness for treatment of cocaine and opiate dependence. The extent to which these findings with naltrexone, a long-acting $\mathrm{mu}$ opioid antagonist, are applicable to naloxone, a shortacting mu opioid antagonist is unknown. Naloxonebuprenorphine combinations attenuated the subjective and physiologic effects of buprenorphine alone but did not compromise buprenorphine's analgesic effectiveness in persons who were not opiate-dependent (Strain et al. 1992; Rolly et al. 1986). In methadonedependent men, naloxone-buprenorphine combinations induced abstinence signs similar to the effects of naloxone alone (Preston et al. 1988). In preclinical studies, naloxone pretreatment antagonized buprenorphine's effects on a variety of behavioral measures (Dykstra, 1983; Shannon et al. 1984; DeRosett and Holtzman, 1984). There is considerable clinical evidence that buprenorphine reduces cocaine abuse in opiate-dependent patients (Kosten et al. 1989; Rosen and Kosten 1991) as well as in polydrug abusers dependent on both cocaine and opiates (Gastfriend et al. 1992, 1993a, 1993b). The concordance between preclinical and ongoing clinical evaluations of buprenorphine treatment suggests the value of animal models of drug self-administration for predicting the effectiveness of new pharmacotherapies for drug abuse treatment (Mello et al. 1993a, 1993b; Mello, 1992).

\section{ACKNOWLEDGMENTS}

This research was supported in part by Grants DA02519, DA04059, DA00101, DA00064, and DA00115 from the National Institute on Drug Abuse. We thank Nicolas DiazMigoyo, Joseph Pocher, and Sandra Hitz for excellent technical assistance in data collection. We are grateful to Mark 
Dobrosielski for operant system design and computer assistance and J. Wallis Sholar for assistance in graphics and statistical evaluations. Preliminary data were presented to the American College of Neuropsychopharmacology in 1991 and to the College on Problems of Drug Dependence in 1992. We thank Dr. John W. Lewis of Reckitt and Colman Ltd. for his valuable consultation on this project, and Drs. Mark J. Kaufman and S. Stevens Negus of the Alcohol and Drug Abuse Research Center, McLean Hospital and Harvard Medical School for their helpful comments on the manuscript.

\section{REFERENCES}

Bickel WK, Stitzer ML, Bigelow GE, Liebson IR, Jasinski DR, Johnson RE (1988): A clinical trial of buprenorphine: Comparison with methadone in the detoxification of heroin addicts. J Clin Pharmacol Ther 43:72-78

Brown EE, Finlay JM, Wong JTF, Damsa G, Fibiger H (1991): Behavioral and neurochemical interactions between cocaine and buprenorphine: Implications for the pharmacotherapy of cocaine abuse. J Pharmacol Exp Ther 256:119-126

Bullingham RES, McQuay HJ, Moore A, Bennett MRD (1980): Buprenorphine kinetics. Clin Pharmacol Ther 28:667-672

Carroll ME, Lac ST (1992): Effects of buprenorphine on selfadministration of cocaine and a non-drug reinforcer in rats. Psychopharmacology 106:439-446

Carroll ME, Carmona GN, May SA, Buzalsky S, Larson C (1992): Buprenorphine's effects on self-administration of smoked cocaine base and orally delivered phencyclidine, ethanol and saccharin in rhesus monkeys. J Pharmacol Exp Ther 261:26-37

Cowan A, Doxey JC, Harry EJR (1977): The animal pharmacology of buprenorphine, an oripavine analgesic agent. Br J Pharmacol 60:537-545

DeRosett SE, Holtzman SG (1984): Effects of naloxone, diprenorphine, buprenorphine and etorphine on unpunished and punished food-reinforced responding in the squirrel monkey. J Pharmacol Exp Ther 228:669-675

Drieze JM, Mello NK, Lukas SE, Mendelson JH (1993): Buprenorphine attenuates cocaine's reinforcing properties in rhesus monkeys. Harris LS (ed), Problems of Drug Dependence 1992, Washington, D.C., U.S. Government Printing Office (In press)

Dykstra LA (1983): Behavioral effects of buprenorphine and diprenorphine under a multiple schedule of food presentation in squirrel monkeys. J Pharmacol Exp Ther 2:317-323

France CP, Woods JH (1989): Discriminative stimulus effects of naltrexone in morphine-treated rhesus monkeys. J Pharmacol Exp Ther 250:937-943

France CP, Jacobson AE, Woods JH (1984): Discriminative stimulus effects of reversible and irreversible opiate agonists: Morphine, oxymorphazone and buprenorphine. J Pharmacol Exp Ther 230:652-657

France CP, De Costa BR, Jacobson AE, Rice KC, Woods JH (1990): Apparent affinity of opioid antagonists in morphine-treated rhesus monkeys discriminating between saline and naltrexone. J Pharmacol Exp Ther 252:600-604

Fudala PJ, Jaffe JH, Johnson RE (1991): Outpatient compari- son of buprenorphine maintenance. II. Effects on cocaine usage, retention time in study and missed clinic visits. NIDA Res Monograph 105:587-588

Gastfriend DR, Mendelson JH, Mello NK, Teoh SK (1992): Preliminary results of an open trial of buprenorphine in the outpatient treatment of combined heroin and cocaine dependence. NIDA Res Monograph 119:461

Gastfriend DR, Mendelson JH, Mello NK, Teoh SK, Reif S (1993a): Buprenorphine pharmacotherapy for concurrent heroin and cocaine dependence. Am J Addictions (In press)

Gastfriend DR, Wapler M, Teoh SK, Reif S, Mendelson JH, Mello NK (1993b): Effects of buprenorphine on needle sharing, drug use and drug craving in men with combined heroin and cocaine dependence. NIDA Res Monograph 132:312

Gmerek DE, Dykstra LA, Woods JH (1987): Kappa opioids in rhesus monkeys. III. Dependence associated with chronic administration. J Pharmacol Exp Ther 242:428-436

Goldberg SR, Morse WH, Goldberg DM (1981): Acute and chronic effects of naltrexone and naloxone on schedulecontrolled behavior of squirrel monkeys and pigeons. J Pharmacol Exp Ther 216:500-509

Hammer RP (1989): Cocaine alters opiate receptor binding in critical brain reward regions. Synapse 3:55-60

Hoffmeister F (1986): Negative reinforcing properties of naloxone in the non-dependent rhesus monkey: Influence on reinforcing properties of codeine, tilidine, buprenorphine, and pentazocine. Psychopharmacology 90:441450

Holland MJ, Carr RD, Simon EJ (1989): Pharmacokinetics of $[3 \mathrm{H}]$-buprenorphine in the rat. Res Commun Chem Pathol Pharmacol 64:3-16

Holman RB, Lewis JW, Lalies MD (1993): Acute and chronic buprenorphine treatment: Dopamine release in nucleus accumbens of conscious rats. Harris LS (ed), Committee on Problems of Drug Dependence 1992, Washington, D.C., U.S. Government Printing Office (In press)

Ishizuka Y, Rockhold RW, Hoskins B, Ho IK (1988): Cocaineinduced changes in $3 \mathrm{H}$-naloxone binding in brain membranes isolated from spontaneously hypertensive and Wistar-Kyoto rats. Life Sci 43:2275-2282

Jaffe JH, Martin WR (1990): Opioid analgesics and antagonists. In Gilman AG, Rall TW, Nies AS, Taylor P (eds), The Pharmacological Basis of Therapeutics. New York, Pergamon Press, pp 485-521

Jasinski DR, Henningfield JE, Hickey JE, Johnson RE (1983): Progress Report of the NIDA Addiction Research Center, Baltimore, MD. NIDA Res Monograph 43:92-98

Johanson CE, Fischman MW (1989): The pharmacology of cocaine related to its abuse. Pharmacol Rev 41:3-52

Johnson RE, Jaffe JH, Fudala PJ (1992): A controlled trial of buprenorphine treatment for opioid dependence. JAMA 267:2750-2755

Kawai R, Sawada Y, Channing M, Dunn B, Newman AJ, Rice KC, Blasberg RG (1990): Kinetic analysis of the opiate antagonist cyclofoxy in rat brain: Simultaneous infusion of active and inactive enantiomers. J Pharmacol Exp Ther 255:826-835

Kosten TR, Kleber HD (1988): Buprenorphine detoxification 
from opioid dependence: A pilot study. Life Sci 42 : 635-641

Kosten TR, Kleber HD, Morgan C (1989a): Role of opioid antagonists in treating intravenous cocaine abuse. Life Sci 44:887-892

Kosten TR, Kleber HD, Morgan C (1989b): Treatment of cocaine abuse with buprenorphine. Biol Psychiatry 26: 170-172

Kosten TR, Krystal JH, Charney DS, Price LH, Morgan CH, Kleber HD (1990): Opioid antagonist challenges in buprenorphine maintained patients. Drug Alcohol Depend 25:73-78

Kuhar MJ, Ritz MC, Sharkey J (1988): Cocaine receptors on dopamine transporters mediate cocaine reinforced behavior. NIDA Res Monograph 88:14-22

Leander JD (1987): Buprenorphine has potent kappa opioid receptor antagonist activity. Neuropharmacology 26: 1445-1447

LeeMC, Wagner HNR, Tanada S, Frost JJ, Bice AN, Dannals RF (1988): Duration of occupancy of opiate receptors by naltrexone. J Nuclear Med 29:1207-1211

Lewis JW, Rance MJ, Sanger DJ (1983): The pharmacology and abuse potential of buprenorphine: A new antagonist analgesic. Behav Biol Res 3:103-154

Line $S$ (1987): Environmental enrichment for laboratory primates. JAVMA 90:854-859

Line S, Markowitz H, Morgan K, Strong S (1989): Evaluation of attempts to enrich the environment of single-caged non-human primates. In Driscoll JW (ed), Animal Care and Use in Behavioral Research: Regulations, Issues, and Applications. Beltsville, MD, National Agricultural Library, pp 103-117

Lizasoain I, Leza JC, Lorenzo P (1991): Buprenorphine: Bellshaped dose-response curve for its antagonist effects. Gen Pharmac 22:297-300

Lloyd-Jones JG, Robinson P, Henson R, Biggs SR, Taylor T (1980): Plasma concentration and disposition of buprenorphine after intravenous and intramuscular doses to baboons. Eur J Drug Metab Pharmacokinet 5:233-239

Lukas SE, Mello NK, Drieze JM, Mendelson JH (1993): Modulation of the reinforcing effects of cocaine by buprenorphine in rhesus monkeys. (Submitted)

Martin WR, Jasinski DR, Mansky PA (1973): Naltrexone, an antagonist for the treatment of heroin dependence effects in man. Arch Gen Psychiatry 28:784-791

Mello NK (1992): Behavioral strategies for the evaluation of new pharmacotherapies for drug abuse treatment. NIDA Res Monograph 119:150-154

Mello NK, Mendelson JH (1993a): Buprenorphine'seffects on cocaine and heroin abuse. In Korenman S, Barchas J (eds), The Biological Basis of Substance Abuse. New York, Oxford University Press, pp 463-485

Mello NK, Mendelson JH (1993b): Buprenorphine treatment of cocaine and heroin abuse. In Cowan A, Lewis J (eds), Buprenorphine. New York, John Wiley \& Sons (In press)

Mello NK, Mendelson JH, Kuehnle JC, Sellers ML (1981): Operant analysis of human heroin self-administration and the effects of naltrexone. J Pharmacol Exp Ther 216: 45-54
Mello NK, Mendelson JH, Bree MP, Lukas SE (1989): Buprenorphine suppresses cocaine self-administration by rhesus monkeys. Science 245:859-862

Mello NK, Mendelson JH, Bree MP, Lukas SE (1990): Buprenorphine and naltrexone effects on cocaine self-administration by rhesus monkey. J Pharmacol Exp Ther 254:926-939

Mello NK, Lukas SE, Kamien JB, Mendelson JH, Drieze J, Cone EJ (1992): The effects of chronic buprenorphine treatment on cocaine and food self-administration by rhesus monkeys. J Pharmacol Exp Ther 260:1185-1193

Mello NK, Kamien JB, Lukas SE, Drieze J, Mendelson JH (1993a): The effects of nalbuphine and butorphanol treatment on cocaine and food self-administration by rhesus monkeys. Neuropsychopharmacology 8:45-55

Mello NK, Mendelson JH, Lukas SE, Gastfriend D, Teoh SK, Holman BL (1993b): Buprenorphine treatment of opiate and cocaine abuse: Clinical and preclinical studies. Harvard Rev Psychiatry (In press)

Negus SS, Dykstra LA (1988): Kappa antagonist properties of buprenorphine in the shock titration procedure. Eur J Pharmacol 56:77-86

Negus SS, Picker MJ, Dykstra LA (1990): Interactions between $\mathrm{mu}$ and kappa opioid agonists in the rat drug discrimination procedure. Psychopharmacology 102:465-473

Negus SS, Picker MJ, Dykstra LA (1991): Interactions between the discriminative stimulus effects of mu and kappa opioids in the squirrel monkey. J Pharmacol Exp Ther 256: 149-158

Ostrowski NL, Burke TRJ, Rice KC, Pert A, Paul CB (1987): The pattern of $\left[{ }^{3} \mathrm{H}\right]$ cyclofoxy retention in rat brain after in vivo injection corresponds to the in vitro opiate receptor distribution. Brain Res 402:275-286

Pechnick RN, George R, Poland R (1985): The effects of the acute administration of buprenorphine hydrochloride on the release of anterior pituitary hormones in the rat: Evidence for the involvement of multiple opiate receptors. Life Sci 37:1861-1868

Preston KL, Bigelow GE, Liebson IA (1988): Buprenorphine and naloxone alone and in combination in opioid-dependent humans. Psychopharmacology 94:484-490

Preston KL, Sullivan JH, Strain EC, Bigelow GE (1993): Enhanced cocaine effects during methadone maintenance. Harris LS (ed), Problems of Drug Dependence 1992, Washington, D.C., U.S. Government Printing Office (In press)

Richards ML, Sadee W (1985): Buprenorphine is an antagonist at the kappa opioid receptor. Pharmacol Res 2:178-181

Rolly G, Poelaert J, Mungroop H, Paelinck H (1986): A combination of buprenorphine and naloxone compared with buprenorphine administered intramuscularly in postoperative patients. J Int Med Res 14:148-152

Rosen MI, Kosten TR (1991): Buprenorphine: Beyond methadone? Hospital Commun Psychiatry 42:347-349

Sawada Y, Kawai R, McManaay M, Otsuki H, Rice KC, Patlak CS, Blasberg RG (1991): Kinetic analysis of transport and opioid receptor binding of $\left[{ }^{3} \mathrm{H}\right](-)$-cyclofoxy in rat brain in vivo: Implications for human studies. J Cereb Blood Flow Metab 11:183-203

Shannon HE, Cone EJ, Gorodetzky CW (1984): Morphine- 
like discriminative stimulus effects of buprenorphine and demethoxybuprenorphine in rats: Quantitative antagonism by naloxone. J Pharmacol Exp Ther 229:768-774

Shiue C-Y, Bai L-Q, Teng R-R, Arnett CD, Dewey SL, Wolf AP, McPherson DW, Fowler JS, Logan J, Holland MJ, Simon EJ (1991): A comparison of the brain uptake of $N$-(Cyclopropyl $\left[{ }^{11} \mathrm{C}\right]$ methyl)Norbuprenorphine $\left(\left[{ }^{11} \mathrm{C}\right] \mathrm{Bu}-\right.$ prenorphine) and $N$-(Cyclopropyl $\left[{ }^{11} \mathrm{C}\right]$ methyl)Nordiprenorphine $\left(\left[{ }^{11} \mathrm{C}\right]\right.$ Diprenorphine) in baboon using PET. Nucl Med Biol 18:281-288

Strain EC, Preston KL, Liebson IA, Bigelow GE (1992): Acute effects of buprenorphine, hydromorphone and naloxone in methadone-maintained volunteers. J Pharmacol Exp Ther 261:985-993

Stretch R (1977): Discrete-trial control of cocaine self-injection behaviour in squirrel monkeys: Effects of morphine, naloxone, and chlorpromazine. Can J Physiol Pharmacol 55: 778-790

Unterwald EM, Horne-King J, Kreek MJ (1992): Chronic cocaine alters brain mu opioid receptors. Brain Res 584: 314-318
Verebey K, Volavka J, Mule SJ, Resnick RB (1976): Naltrexone: Disposition, metabolism and effects after acute and chronic dosing. Clin Pharmacol Ther 20:315-328

Warren PH, Morse WH (1989): Environmental determinants of enhanced sensitivity to the behavioral effects of naltrexone. J Pharmacol Exp Ther 248:546-551

Weinhold LL, Preston KL, Farre M, Liebson IA, Bigelow GE (1992): Buprenorphine alone and in combination with naloxone in non-dependent humans. Drug Alcohol Depend 30:263-274

Wilson MD, Schuster CR (1970): Pharmacological modification of psychomotor stimulant self-administration in the rhesus monkey. Fed Proceed 29:749

Winger G, Skjoldager P, Woods JH (1992): Effects of buprenorphine and other opioid agonists and antagonists on alfentanil- and cocaine-reinforced responding in rhesus monkeys. J Pharmacol Exp Ther 261:311-317

Witkin JM, Johnson RE, Jaffe JH, Goldberg SR, Katz JL (1991): The partial opioid agonist, buprenorphine, protects against the lethal effects of cocaine. Drug Alcohol Depend 27:177-184 